\title{
Conceptual Model for Examining Knowledge Maps Adoption in Software Development Organizations
}

\author{
Ali Balaid ${ }^{1}$, Mohd Zaidi Abd Rozan ${ }^{1} \&$ Syed Norris Abdullah ${ }^{1}$ \\ ${ }^{1}$ Faculty of Computing, Department of Information Systems, Universiti Teknologi Malaysia, Johor, Malaysia \\ Correspondence: Ali Balaid, Faculty of Computing, Universiti Teknoligi Malaysia (UTM), Block N28a, Skudai, \\ JB, Malaysia. Tel: 60-87-68-1787. E-mail: ali_balaid@yahoo.com
}

Received: May 11, 2014 Accepted: June 4, 2014 Online Published: July 11, 2014

doi:10.5539/ass.v10n15p118 URL: http://dx.doi.org/10.5539/ass.v10n15p118

\begin{abstract}
A knowledge map has emerged, as a powerful source of competitive advantage, and plays an important role in managing an organizational knowledge. The definition, purposes, benefits, types and principles of knowledge map have been already provided and well explored by many scholars and researchers. However, predictors for a knowledge map adoption have seldom been addressed. Hence, how to facilitate a successful adopting of a knowledge map becomes important. To address this gap this study develops a conceptual model to investigate diverse factors influencing the adoption of knowledge map in software development organizations context. The research proposed model is established on the Technological-Organizational-Environmental (TOE) framework. The model identifies thirteen variables, covering five broad categories (Technological, Organizational, Environmental, Task, and Individual) that could potentially influence knowledge map adoption. A complete analysis of the possible aspects to be considered for adopting of knowledge map in software development organizations is provided by the proposed model.
\end{abstract}

Keywords: knowledge maps, TOE framework, TTF model, UTAUT

\section{Introduction}

A knowledge map is a significant and efficient instrument ought to assist an organizational unit, a team or an individual employee in using and understanding the entire knowledge available in an organizational site (Eppler, 2001). A knowledge map, not only makes knowledge and experts approachable over visual aid interfaces, but also provides a generic context or framework to which the company employees can relate to in their exploration for important knowledge (Wexler, 2001). It identifies what knowledge the organization already has, who has this knowledge and how they can use the knowledge (Wexler, 2001; Davenport et al., 2000). Knowledge map, prevent the reinvention of the wheel and capture new knowledge by removing unnecessary actions, identifying best practice, encourage the re-use of ideas, and avoiding duplication of tasks (Renukappa \& Egbu, 2004). On top, knowledge map techniques showing beneficial results when it was utilized in organizations particularly in software companies as it provides a snapshot of where an organization is at any given time relative to its competitors (Vail, 1999; Tiwana, 1999).

A further benefit, knowledge map provides the right path to find the right knowledge sources for instance, in software organizations, staffs often have to search for knowledge in different sources, sometimes they not knowing who to contact or where to look when they try to find some help. Since, the knowledge of software development is known only by the expert or is buried in the company's databases, and documentation is very hard to retrieve if the appropriate person who knows where to find it is not around (Joseph Lee \& Dieter Fink, 2013; Hansen \& Kautz, 2004; Fahey \& Prusak, 1998). Here, it is obvious locating the right route to the right sources of knowledge has been tricky in the software organizations. Therefore, to resolve many of the software organizations traceability problems knowledge maps might be ideally suited. Hansen and Kautz (2004) concluded that mapping techniques afford supportive means to recognize knowledge flows complexity in a software development organization with a number of simultaneous projects.

However, in spite of the espoused benefits of knowledge map, the adoption of knowledge map is still in its infancy (Wang et al., 2012). The majority of studies on knowledge map have been done from the point of developers, rather than of knowledge managers and/or users (Lee \& Dieter Fink, 2013). In other words, the mainstream of the current knowledge maps research generally focuses on the technical aspects of mapping with 
a particular dearth of discussion on the factors that influencing the adoption of knowledge map (Lee \& Fink, 2013; Wang, 2012). Research on the adoption of knowledge maps appears to be one of the less examined and researched themes in the domains of IS until now, there has been very little reporting on knowledge map adoption in the literature (Wang, 2012; Dang, 2011) this emphasizes the need for more studies in this area.

Responding to the highlighted lack of research, our study aims to fill this gap by proposing a conceptual research model that can be utilized to investigate diverse factors affecting knowledge maps adoption in software development companies context. The proposed model would provide a more comprehensive of what factors affect organizational adoption of knowledge maps. The theoretical groundwork of this research derives from the combination of the Technological-Organizational-Environmental (TOE) framework, the Unified-Theory of Acceptance and Use of Technology 2 (UTAUT2) and Task-Technology-Fit (TTF) Model. The resulting model consists of thirteen factors that were found significant in most cases of priori studies on the adoption of IT innovations by organizations. The factors covering five broad contexts (technological, organizational, environmental, individuals and task) that could potentially influence knowledge map adoption. The conceptual model is proposed to shed light on our main question of the research, which asks, "What are the factors (technological, organizational, environmental, task and individual) that influencing knowledge maps adoption in the context of software development organizations?"

The remainder of this article proceeds in this manner: the subsequent section discusses the theoretical background with brief analyses of TOE framework, TTF model and the UTAUT theory. The following section presents a description of the research model development with the relevant literature on which our model was based on. Then the main factors with the associated hypothesis will be expounded in the subsequent section. In the end, the conclusion, and potential research directions are presented.

\section{Theoretical Background}

To smooth the way for developing a model for knowledge maps adoption by organizations, the related literature on the TOE (Technology-Organization-Environment) framework, UTAUT2 (Unified-Theory of Acceptance and Use of Technology 2) and TTF (Task-Technology-Fit) Model were examined.

\subsection{Technology-Organization-Environment (TOE) Framework}

TOE framework, was originally initiated by Tornetzky and Flaischer (1990) based on the Contingency Theory of Organizations. Tornetzky and Flaischer (1990) posit that the adoption of an IT innovation by organizations is under the effect of three main context groups: technological-context, organizational-context, as well as environmental-context. As well, they argued that each one of these contexts influences organization in its adoption decisions. Thus, they introduced a TOE framework to find out what determinates essentially influence organization's adoption decisions. The technological context refers to both existing/new technologies and to interior/exterior technologies, which are related to the organization. It portrays the characteristics of an IT innovation such as innovation compatibility, innovation complexity and innovation relative advantages, which considerably affecting an innovation adoption (Tornetzky \& Flaischer, 1990; Melville \& Ramirez, 2008; Dooln et al., 2007). The organizational context indicates to organization characteristics, such as organization size, organization scope, organization culture and the degree of top management support (Low et al., 2011). The environmental context is the arena in which an organization carry outs its business, including organization competitors and dealings with the government's policies and regulations (Oliveira \& Martins, 2010).

TOE framework, has been examined and proven to be a successful framework for analyzing the organizational adoption by many studies (e.g. Saedi \& Iahad, 2013; Yoon, \& George, 2013; Alatawi, 2012; Zheng, 2011; Oliveira \& Martins, 2010; Te, 2006; Ramdani, 2009; Zh. \& Kraem., 2005; He \& Wei, 2004; Ryan \& Prybutok, 2001; Kua. \& Cha., 2001; Ryan et al., 2000). Overall, priori studies on IT adoptions found TOE provided a complete analysis for the determinates of the technological, organizational and environmental contexts. However, TOE does not intend to offer a fixed model, including specific factors that may affect the adoption processes; it is actually a taxonomy for categorizing factors in their relevant context (Ve. \& Verel., 2011). The major significance of the TOE is that it induces the researchers to consider the broader context in which the study of adoption carry outs (Ve. \& Verel., 2011). In view of various points of TOE Rya. and Prybut (2001), made changes to it to make it well-suited with knowledge management techniques adoption. Wei and He. (2004), also utilized TOE as an introductory point and proposed some factors in each context to clarify more specifically organizational adoption. Ramdni et al. (2009) utilized this framework for proposing a model to examine SMEs adoption of enterprise systems. Yet, a number of researchers recommended that to identify specific factors for organizational, technological as well as environmental context and to build the underlying relationships between these factors, the TOE framework should be integrated with other theories (Alatawi et.al., 2012; Chon. \& Cha., 
2012; Henderson et.al., 2012; Aw. et.al., 2011). Integrating other theories or models with TOE provides richer theoretical lenses to the understanding of adoption behavior and offering more number of constructs than the original.

Drawing upon these pragmatic evidences, from the literature review about TOE framework we believe that it is a much more appropriate analytical tool to categorize and better explains all determinants of knowledge map adoption. Thus, in this study, we adopted TOE framework and extended it to the knowledge map domain, by combining it with other theories (TTF and UTAUT 2) which has not been done in the literature.

\subsection{Task-Technology-Fit (TTF) Model}

TTF-Model was developed by Goodhu and Thompson (1995), derived from the Theory of Cognitive Fit. TTF point out to the matching of the demands of the task and the capabilities of the technology that is the aptness of the technology to carry out a task. TTF model postulates that the fit between technology functionality and the requirements of the task influences adoptions and performance (Goodhu \& Thompson, 1995). In other words, technologies will be adopted and utilized well if, and only if, their functions can achieve user's tasks and needs (Dishaw, 2002; Goodhue, 1998). According to (Gupta, 2003) a little capability of technology with task requirements, might not result in benefits, while the technology is useless when it is behind the requirements of the task. Goodhue and Thompson (1995) found that task complexity and interdependence are the dimensions of task that matter for their domain.

Overall, priori studies revealed that the TTF model is generally useful in expounding technology adoption in different domains (e.g. Shih \& Chen, 2013; Liu \& Goodhue, 2012; Yen, et.al., 2010; Larse, et.al., 2009; Strong, et.al., 2006; Klopping \& McKinney, 2004; Dishaw, et.al., 2001; Goodhue, et al., 1997). On top of that, some studies have integrated TTF model with other models, for example Dishaw and Strng (1999), integrated TAM model with TTF model. The findings proven that the synthesis of TAM and TTF elucidates further variance than either model alone. Likewise, Huang and Lin (2008), incorporated SCT with TTF model and yield more explains about KM system utilization and usage. However to our knowledge, there is no study, have been used TOE with TTF to evaluate knowledge map adoption. The present study combined TTF with TOE framework to measure the effect of task characteristics on knowledge map adoption.

\subsection{Unified Theory of Acceptance and Use of Technology (UTAUT)}

Venkatesh et.al. (2003), placed the unified model that incorporates constructs from across eight models of technologies acceptance based on empirical as well as conceptual similarities. Venkatesh et.al. (2003), indicates that UTAUT represents a complete model for IT innovation acceptance and outperforms all eight models of individual in their review, by explaining seventy percent (70\%) of the variance in behavioral intention to accept and utilizing of technologies. Accordingly, UTAUT was formulated from the Theory of Reasoned-Action (TRA), the Theory of Planned-Behavior (TPB), the Technology Acceptance Model (TAM), the combined TPB and TAM, the Motivational Model (MM), the Model of PC-Utilization (MPTU), the Social-Cognitive-Theory (SCT) and the Innovation Diffusion Theory (IDT). The resulting UTAUT model consists of four factors; social influence, performance expectancy, facilitating conditions and effort expectancy, that are directly associated with the factor of behavioral intention to accept a technology that's consequently influence the decision of users to adopt a technology. Consistent with the common ideas delineated by Johns (2006), and by Alvesson and Kärrem. (2007), regarding how to extend a theory by leveraging a novel context, Venkatesh and Thong and Xu (2012), placed UTAUT2 by identifying three salient constructs from priori studies on adoption and use technologies (i.e., hedonic motivation, habit, and price value). The main idea of the UTAUT and UTAUT2 was to get a cohesive view of user technology adoption and use (Venkatesh et.al., 2012).

UTAUT has been employed in a wide range of studies in several domains. For instance Anderson et.al. (2006) utilized UTAUT to discover the drivers of user acceptance of tablet PCs amongst peoples in higher education; Carlss. et.al. (2006) utilized UTAUT to clarify m-services/devices acceptance in Finland; Al-Awadhi and Morris (2008) used UTAUT to predict e government services acceptance; Yang (2010) and Lu,Yu, and Liu (2009) used UTAUT to explain mobile application acceptance. Further, UTAUT was used in information technology adoption in general (e.g. Zhou, 2012; Wang \& Shih, 2009; Uzoka, 2008; Al-Gahtani, 2007; Neufeld, 2007). UTAUT has been extended to suit several contexts, and applied to a number of different types of systems. Overall, priori studies revealed that the UTAUT theory is generally valuable in clearing up user's adoption and use of technology.

Since UTAUT has been established as one of the most widely accepted models that used to predict the factors that influencing IT innovation adoption, this research combined UTAUT2 with TOE framework through considering two individual factors from UTAUT2 (i.e. Social influence, Hedonic motivation) that may affect 
knowledge map adoption. Furthermore, this study tags on the call of Venkatesh et.al. (2012), for more future research to examine the UTAUT2 for diverse technologies. Besides, UTAUT2 has neither been examined under the domain of a TOE framework at any organizational level in adoption research on knowledge map adoption; it would be motivating to detect its influence in knowledge maps adoption context.

\section{Research Model and Hypothesis Development}

The exploration of the theories underpin the understanding of an IT innovation adoption in organizations shows that they predominantly turn around the Innovation and Diffusion Theory (IDT), Theory of Reasoned Action (TRA), Theory of Planned Behavior (TPB), Technology Acceptance-Model (TAM), TOE framework, UTAUT and recently UTAUT2. These theories, have been applied in different domains such as knowledge management (Huan, 2O11; Xu \& Quaddu, 2011; Hester, 2010), e-commerce (Gibbs \& Kraemer, 2004), enterprise system (Ramdni et.al., 2009), collaborative commerce (Chon., et.al. 2009), RFID (Radio Frequency Identification) (Wan., et.al., 2010), systems of e-procurement (Liu 2OO8), and e-business systems (Oliveira \& Martins, 2011; Zhu et al., 2006).

Accordingly, after exploring the literatures in depth, with an attentive analysis of various models and theories has been the groundwork for choosing the Technological-Organizational-Environmental (TOE) as a guiding framework for this study. TOE, has been tested and verified to be a successful framework for analyzing the organizational adoption by many studies (e.g. Saedi, \& Iahad, 2013; Yoon, \& George, 2013; Alatawi, 2012; Oliveir. \& Martin., 2010; Ramdani, 2009; Teo, 2004; Zhu \& Kraemer, 2006; Kua. \& Cha, 2001). Moreover, Zhu., et.al. (2003) claimed that, TOE is a generic theory of IT innovation adoption. However, TOE framework does not endeavor to present a specified model, including specific factors that control the adoption processes; it is in fact a taxonomy for categorizing factors into their relevant context (Ve. \& Verels., 2011). The most important contribution of the TOE is that it motivates the researchers to consider the broader context in which the study of adoption takes place (Ve. \& Verels., 2011).

Thus, this study will use the TOE framework to build up a conceptual model that can be used to envisage which factors are more expected influencing the adoption of knowledge maps in the context of software organizations. Despite aforementioned researches, that have established robust empirical support for the TOE-framework, much fruitful theoretical work remains to be carried out. Researchers have suggested that not only should the organizational, technological, and environmental contexts be considered, but also that individual and task characteristics should be included in studies of adoption (Baker, 2012; Premkumar, 2003). Here, consistent and in keeping with Baker's (2012) and Premkumar's (2003) general ideas regarding how to extend and enrich the TOE framework, we accomplish this goal by identifying tasks and individual contexts under the TOE framework to explore in which way they influenced the knowledge map adoption in software development organizations. In fact, integrating TOE with other theories or models provides richer theoretical lenses to understand adoption themes and presenting a bigger number of constructs than the original (Awa et al., 2011). Therefore, the proposed model is developed by integrating two other theories, to the TOE framework, including the TTF, and the UTAUT2 theories. The resulting conceptual model consists of thirteen factors that have been picked very carefully due to the empirical background and solid theoretical. The factors covering five broad contexts (technological, organizational, environmental, task, and individual) that could potentially influence knowledge maps adoption.

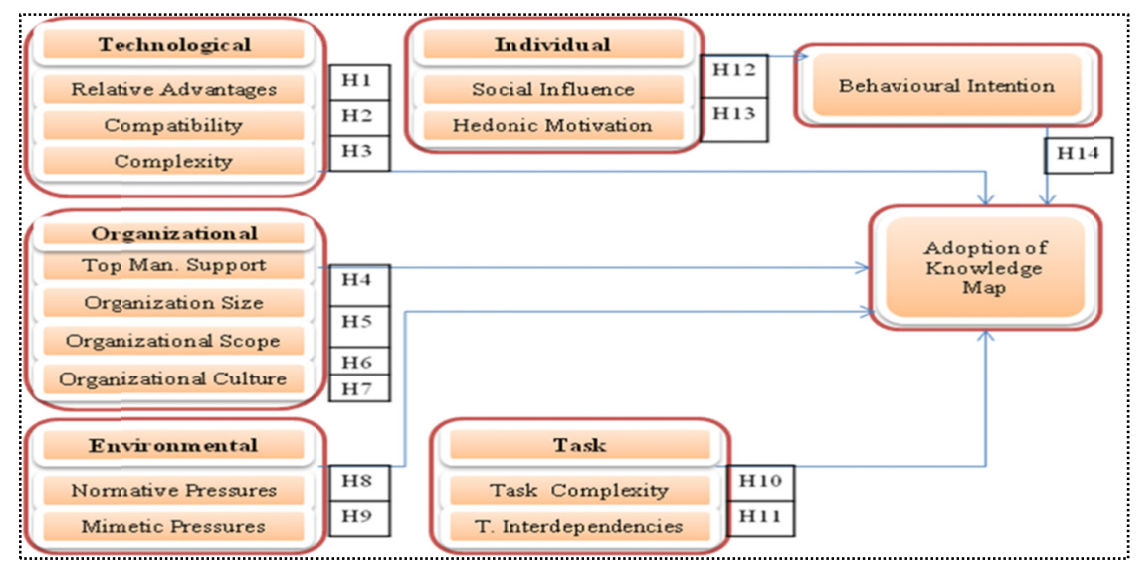

Figure 1. The proposed Conceptual model for knowledge maps adoption 


\subsection{Technological-Context}

This context normally explains the characteristics of IT innovations that affect on the organizational adoption decision (Thong, 1999). This research used Rogers' (2003) innovation diffusion theory as a theoretical foundation for studying the technologies factors and their impact on software organizations' intention to adopt knowledge maps. Three technological characteristics considered in this study, including relative advantages, compatibility and complexity of the knowledge map.

\subsubsection{Relative-Advantage}

In line with DOI theory, relative advantage is described as the amount to which using IT innovations is discerned as being preferable than using its antecedent (Roger, 2003). In the literature, the measure of relative-advantage is frequently identified as the degree of the perceived benefits that the organization may receive from the innovation (e.g. Hendersn et.al., 2O12; Yoon, 2009; Iacovo et.al., 1995). From different models, the five constructs that pertain to relative advantage are performance-expectancy (UTAUT), perceived-usefulness (TAM \& C-TAM-TPB), job-fit (MPCU), outcome-expectations (SCT) and extrinsic-motivation (MM). Even as these constructs evolved in the literature, their similarities are recognized by some authors: relative advantage and usefulness (Plouf. et.al. 20O1; Moor. \& Benbasa. 1991; Davis et.al. 1989) extrinsic-motivation and usefulness (Davis et.al. 1992, 1989), job-fit and usefulness (Thompson et.al. 1991), outcome expectations and usefulness (Compeau \& Higgins 1995b; Davis et.al. 1989). In agreement with DOI theory, previous studies on the adoption of IT innovations repeatedly found relative-advantage positively influencing organizations adoption of IT innovations (Cragg, \& Mills, 2001; Chewl. et.al., 2001; Mehrten., Tornotzky \& Klein, 1982). Likewise, prior studies that utilized TOE as well recommended relative-advantage as one of the most significant factors that influences organization adoption of an innovation (e.g. Yoon, T. E., \& George, J. F. 2013; Low et al., 2011; Ghobakhloo et.al., 2011; Hung et.al., 2010; Shiau et.al., 2009; Ramdani et.al., 2009; Seyal et.al., 2007; Al-Qirim, 2007; Thong, 1999; Premkumar \& Roberts, 1999). Consequentially, it is extremely possible that when organizations perceived the benefits of an innovation, they are more interested to adopt that innovation.

Since, knowledge maps provide several benefits, particularly to software development organizations in terms of knowledge identification, communication, training and collaboration. With regard to knowledge identification, knowledge map provides a visual representation of the organizational knowledge inventory. It shows what knowledge assets are at the organization's disposal, where they are located within the enterprise and how these assets can be accessed and used towards solving operational problems, besides it contributes to the identification of knowledge gaps or deficits that exist inside an organization. Regarding to communication and collaboration, knowledge map illustrates the dynamic relationships that exist between various knowledge assets within an organization. It shows the different way knowledge is being transferred, the channels through which it circulates, the processes through which it is exchanged, and who the providers and the recipients of knowledge are. With regard to organizational training, knowledge map can show not only the strengths of an organization, but also the areas where it is weaker. According to Soliman \& Spooner (2000) knowledge maps, evaluating what the staff knows against what they should know, besides identifying opportunities for training to overcome existing knowledge deficiencies. Therefore, it is extremely probable that when the benefits of knowledge maps perceived by the organization, the adoption will take place. The following hypothesis, therefore formulated:

H1. Perceived greater relative advantages of knowledge map leads to greater intent to adopt knowledge maps.

\subsubsection{Compatibility}

Compatibility is the measure to which IT innovations is discerned as being consonant with the current values, former experiences, and needs of prospective adopters (Rogers, 2003). The compatibility construct incorporates items that tap the fit between the individual's work style and system use in an organization (Venkateche, 2003). In the literature, there are a number of constructs capture the concept of compatibility such as facilitating-conditions (UTAUT), perceived-behavioral-control (C-TAM-TPB, TPB/ DTPB), as well as facilitating-conditions (MPCU). There is considerable similarity amongst these constructs measurement scales and definitions have been noted in priori studies (Plouffe et al., 2001; Thompson et.al., 1991; Moor \& Benbasat, 1991; Davis et.al. 1989). As well, the empirical evidence presented in the literature confirmed that the relationships between each of the constructs (compatibility, facilitating-conditions and perceived-behavioral-control) and intention are alike.

In agreement with DOI theory, previous studies of IT adoptions found that an innovation, which is compatible with the norms and values of an organization or with the norms of a social system, spreads faster than an innovation, which is not compatible. In fact, organizations are more motivated to adopt an innovation with a high level of compatibility (Shaharudin et al, 2012; Alam, 2009; Fuller et.al., 2007; Al-Qirem, 2007; Hong \& Zh., 
2006; Beatty et.al., 2001; Thong, 1999; Thong, 1999; Premkmar et.al., 1994). Compatibility is an important factors for adoption, for the reason that with a high level of compatibility, minimal change and adjustments needs to be made by the organizations (Thong, 1999). In the same way, Yoon (2009) expressed that, compatibility makes the innovation more meaningful to the potential adopter and suggests lesser risk to the organization. Although a lack of incompatibility may cause low utilization and adoption (Low, et.al., 2011; Alam, 2009). Sharing this view, Hu., (2012) explained the incompatibility of a new technology with an existing value systems, infrastructure and procedures negatively affect users' attitudes and increasing their resistance to change, which in turn deter technology adoption.

In this study, compatibility is defined as the consistency of knowledge maps with existing experiences, values, and needs of software development teams and organizations. Joseph Lee and Dieter Fink (2013) stated that, if the knowledge map were incompatible with staff's experience and the organization's way of doing things, then it would surely impede the adoption of knowledge map. On the contrary, staffers in software development organizations will be more willing to adopt a knowledge map if it is compatible with their work norms and experiences. For similar reasons, we assume that:

H2. Greater compatibility of the knowledge map leads to greater intent to adopt knowledge maps.

\subsubsection{Complexity}

Complexity expounds the degree to which IT innovations are perceived as relatively complicated to utilize and understanding (Roger, 2003; Thompson et al., 1991). It is analogous to effort expectancy (UTAUT) and in an opposite direction to perceived ease of use (TAM). In prior research, the similarities among these constructs have been noted (e.g.Davis et.al., 1989; Moor. \& Benbasat, 1991; Plouf. et.al., 2001; Thompson et.al., 1991).

In the Literature, complexity is recognized as a major obstacle to an IT innovation adoption (e.g. Saedi, A., \& Iahad, N. A., 2013; Henderson et al., 2012; Low et al., 2011; Azam and Taylor, 2011; Al-Qirim, 2007; Thong, 1999; Teo et al., 1995). As such, many researchers identified complexity as reflecting a match between the skills the organization possessed and the technical skill required to use the innovation (Huy, 2012; Low et al., 2011; Lin, 2008; Rui, 2007; Premkumar et al., 1994;). In view of that, an innovation might be measured as complex by some organizations that lack associated skills and knowledge, but not complex by some organizations that have the required skills and knowledge. Thus, complexity is a fit-based concept between the skills organizations possess and the technical skills required (Ru., 2007). Similarly, Lin (2008) points out that complex innovations require greater resources and skills to adopt, as well as cognitive effort on the potential adopter requires more increased. Hence, the perceived complexity of an innovation technology is expected to influence the decision to adopt them negatively. Huy (2012) expressed that, even though the usefulness of an innovation may appear to the firm, it may not have the necessary expertise to utilize it, thereby, increase the risk in the adoption decision and also creates greater uncertainty for successful implementation. To be more specific, when a technology that is difficult to understand, and use is considered to be complex. In fact, a technology is considered complex if it takes too much effort to be learnt; or if the user should spend too much time to perform its normal duties.

In the context of software development, organization staffs are concerned about the complexity of the knowledge map (Joseph Lee, et al., 2013). If knowledge map is too difficult, complex to use or needs too much maintenance, then it will impede the adoption of knowledge map. In the line with the above discussion, this study believes that knowledge map complexity can function as an inhibitor to adoption decision. The following hypothesis, therefore formulated:

H3: Greater complexity of the knowledge map has a negative impact on knowledge maps adoption.

\subsection{Organizational Context}

Organizational dimaintion touches on the characteristics of an organization which basically consist of organization size, organization scope, complexity of managerial structure, degree of centralization, culture, and amount of slack resources available (Felix \& Tan, 2010). Commonly, it looks at the organization structure that facilitates or constraint the adoption of an innovation (Cha. \& Tam., 1997). Based on the literature, support of the top management, the size of the organization, scope of the organization and organization culture were chosen and assumed to be most suited for analyzing the knowledge map adoption in software organizations.

\subsubsection{Top-Management-Support}

According to Grover (1993), Top-management-support indicates to the amount of support expanded by the superior management to adopt and utilizing IT innovations within an organization. A broad base of literature on IT innovation adaptation predominately views top management as the agency responsible for changing the norms, culture and values inside organizations, and in turn, this enables other members of the organization to 
adapt the new technologies. The norms, culture and values stimulated by the top management permeate to the level of the individual in the form of regulations, routines and procedures, which serve as powerful templates that guide the behavior of individuals (Purv et.al., 2001).

Ordinarily, for justifying the positive relationship between IT innovation adoption and top management support there are two different grounds. Firstly, for smoothing adoption and implementation of an IT innovation, strong top management support ensures the sufficient allocation of organizational resources (human, technical and financial). Secondly, since top management can provide long-term strategic vision, proposals, initiatives, support and the obligation to generate a positive environment for the IT innovation, thus strong management support may reduce the resistance of the organization to adopt an innovation (Quin., 1985). Prior studies on the adoption of IT innovations based on TOE framework have as well revealed that top management support is one of the major predictors for the adoption of IT innovations (e.g. Saedi, \& Iahad, 2013; Yoon \& George, 2013; Alatawi 2012; Nels. \& Shaw, 2003; Lertwongsatien \& Wongpinunwatana, 2003; Lederer \& Mendelow, 1998; Premkumar \& Ramamurthy, 1995). Likewise, Srivastava (1983) articulated that organizational decisions, behavior and strategies are guided by top managers' beliefs. In fact, to adopt and implement knowledge map, organizations may require human, technical and financial resources. In addition, organizations may face user resistance in adopting knowledge maps. Therefore, it is extremely expected that organizations with powerful support from top management are more candidate to adopt knowledge maps than those organizations that scarcity such support. Based on this evidence, we propose that:

H4. Greater support from top management leads to greater intent to adopt knowledge maps.

\subsubsection{Organizational Size}

According to Zhu et al. (2003) organizational size is frequently found to be positive regarding the organizational inclination to adopt an innovation. Founded on a review of more than fifty empirical studies, Jeyraj et.al. (2006) revealed the size of organizational as one of the three top predictors of IT adoption by organizations. Stair \& Reynolds (1998) stated that the more expected reason for the significant positive relationship between IT innovations adoption and organization size might be that, as the size of an organization increases, the task coordination complexity becoming more complicated and its dependence on the knowledge movement may increase, thus the need for technologies are increasing, such as knowledge map. Another, a possible explanation for the affirmative relationship between IT adoption and organizational size could be that, larger organizations have greater slack in resources and are therefore able to allocate greater organizational resources (e.g. human resources, financial and technical) to the new technology adoption (Montaz., 1988).

Organization size, has a broad literature as a major factor in studies on IT innovation adoption in particular, the studies that based on a TOE framework, has been revealed that organizational size positively influenced the organizational adoption of IT innovations (e.g. Ojah \& Mokoaleli-Mokoteli, 2012; Spinellis \& Giannikas, 2012; Tsai \& Tang, 2012; Liu, 2008; Sen \& Sinha, 2008; Janvrin, Bierstaker \& Low, 2008; Hsu et.al., 2006; Gib. \& Kraem, 2004; Zh. et.al., 2003; Grover, 1993; Teo \& Tan, 1998). Since, a number of studies have been used two measures of organizational size; those are the number of employees and revenue. In this study, we used a number of employees as a measure of organization size.

Given the fact that, knowledge map has a great prospective to support communication and collaboration among software development teams. Yet, the adoption of knowledge map might require some organizational resources. For instance, to create a knowledge map team small organizations may need to add employees. While large organizations, may already have a sufficient number of workers to create a team for a knowledge map project. Derived from the above discussion, it can be assumed that larger organizations may be more candidates to adopt a knowledge map. Therefore, it is reasonable to put forward the subsequent hypothesis:

H5. Larger organizational size leads to greater intent to adopt knowledge maps.

\subsubsection{Organizational Scope}

Organization scope is identified as the horizontal extent of the organization's operations (Zh. et.al., 2003). The role of organization scope as an adoption predictor can be explained in terms of communication costs, internal and external costs of coordination (Yoon \& George, 2013). It has been acknowledged that communication and coordination costs increase with the organizational scope due to increase of the administrative tasks and the information processing complexity particularly when organization expand globally (Yoon \& George, 2013; Gurbaxani \& Whang, 1991; Zhu et.al., 2003).

In the case of software development organizations, this relates to communications between management, team leaders and the different groups of staff involved in the processes of the software development, such as 
developers, testers and documentation specialists, all these groups have different needs and concerns. Therefore, an organization with a large scope, generally require a significant technology to facilitate their communication and coordination. Here, where the role of knowledge map shown significant. It is widely recognized that a knowledge map is a suitable means of collaboration and communication (Joseph Lee, et al., 2013; Kim, 2007; Eppler, 2008; Wexler, 2001). According to Wexler (2001) a knowledge map is a 'consciously designed communication medium'. In a software development organization, knowledge map may improve the communications between the different groups of experts and create a culture of cooperation and trust, which is central to the success of any company (Joseph Lee, et al., 2013). Since the utilization of knowledge map can decrease communication and searching costs for both management and staff, and improve collaboration between different teams, organizations with greater scopes are more motivated to adopt a knowledge map. Therefore, it is logical to formulate that:

H6. Greater organization scope leads to a greater intent to adopt knowledge maps.

\subsubsection{Organizational Culture}

According to Herbig \& Dunphy (1994) culture is the sum total of a way of life, pattern of values, traits or behavior of people and it is often seen as the system of all communications involving technical and non-technical staff. This implies that all communication, whether technical or non-technical, is affected by the way people live, where they live and their behavior. Rya. et.al. (2000) expressed that the cultural aspect is the result of the shared experiences and values, which cumulates the experiences of individual into an organizational consciousness.

In the existing literature, many articles have been revealed how culture influences IT adoption at the organizational level. For instance, Hoffm. and Klepp. (2000) articulated that organizations high in solidarity (mercenary cultures) and low in sociability experienced more favorable outcomes with technology adoption than did more networked (low solidarity and high sociability) cultures. A further studies found uncertainty avoidance plays a significant role in IT adoption the logic of these studies is that since IT is inherently risky, those less comfortable with uncertainty will be less likely to adopt and use new technologies. For instance, in a study across 23 countries examining 153 businesses, Pnge. et.al. (2001) found that countries are less likely to adopt frame relay technology when it is high in uncertainty avoidance. In a similar vein, Thatch. et.al. (2003) found that students were less willing to experiment with new information technologies when they are from countries high in uncertainty avoidance. Other studies (Jarvenpa \& Leidn. 1998; Streub 1984; Straub, Brenner, \& Keil, 1997) reflect similar results. As well, a study in Chinese firms and their Western counterparts found organizational culture to be one of the most differential factors in adoption decision-making (Wilhel. \& Xia, 1993; Xu et.al., 2004).

In the context of knowledge map adoption Joseph Lee, et al., (2013) demonstrated that culture differences were important factors to knowledge map adoption particularly, for projects that were developed for overseas customers. For this study, the focus is on the influence of culture on the adoption of knowledge map between software development teams for overseas development. Derived from the above discussion, we believe that culture is a critical variable that may directly, or indirectly, influence knowledge map adoption. As a result, the following hypothesis can be devised:

H7: Organizational culture positively influences the adoption of knowledge maps in software development organizations.

\subsection{Environmental Context}

The environmental context is the arena in which an organization undertakes its business. This incorporates the industry regulations, competitors, as well as treating with government (Tornatzky and Fleischer 1990). To study the impact of environmental factors on the knowledge map adoption DiMaggio and Powell's (1983), institutional theory will be used as a theoretical basis. This study takes into consideration two forms pressures of external environmental: mimetic and normative pressures that may affect knowledge map adoption in software organizations.

\subsubsection{Normative Pressure}

Normative pressure is a type of environmental influences that leading to conformity, it may lead an organization to adopt and practicing a new business that other organization in same positions have already adopted (DiMaggio \& Powell, 1983). According to Deephouse (1996) normative pressures can be stems from a number of sources, such as media, professional associations or trade partners. Once organizations learn constructive values and norms from these sources through direct or indirect relations on the subject of adopting a business 
practice particular, they face normative pressures to adopt the particular business practice and conform to these pressures by adopting it. Since, they recognize that adoption is a proper action (Scot., 2003; Burt, 1982).

Prior studies have shown that IT innovation adoption positively influenced by normative pressures that emerging from diverse aspects of business (e. g. Yoon, T. E., \& George, J. F. 2013; Alatawi et al. 2012; Liu et.al. 2010; Khalifa \& Davison, 2006; Benbasat \& Son, 2007; Teo et.al., 2003; Silva and Figueroa, 2002). In view of that, we emphasize the importance of the normative pressures in knowledge maps adoption context. While no such pressure has been explored in the domain of knowledge map, it would be logical to consider that potential adopters of knowledge map may also be subject to the pressures that arise originally from media, business associations, or professional associations. Therefore, in view of the context of knowledge map adoption in software development organizations, the subsequent hypothesis can be formulated:

H8: Greater normative pressures will lead to a greater intent to adopt knowledge maps.

\subsubsection{Mimetic Pressure}

Mimetic pressures are those that push an organization to mimic the actions and pursuing more like other organizations in its environment (DiMaggio \&Powell, 1983). When, an organization face mimetic pressures in its environment, it conforms to these pressures by follow up the actions of other organizations and may try to fabricate alike products, hold similar suppliers as well as come across with analogous constrictions. Because it does not want to be seen as a laggard to its competitors or stakeholders or because the management of the organization believes that it should follow the action with the aim of reducing fears of losing the advantages of competition since the uncertainty of the action is reduced by the imitation (Burt 1987). Organizations facing these pressures in two ways as stated by Teo et al. (2003) and Haveman (1993) the first occurs when the number of organizations that have taken the same action in its environment increases. The second occurs when an organization perceives the actions of other organizations in the same positions that have adopted a similar practice are beneficial and successful.

Prior studies found that mimetic pressures, including competitive pressure, a major driver for IT adoption (e.g. Oliveira and Martins, 2010a; Ramdani et.al., 2009; Oliveira \& Martins, 2009; Li. \& Lin, 2008; Pan \& Jang, 2008; Oliveira \& Martins, 2008; Son \& Benbasat, 2007; Khalifa \& Davison, 2006; Zh. et.al., 2006; Kraemer \& Zhu, 2005; Gibbs \& Kraemer, 2004 Zh. et.al., 2003; Teo et.al., 2003; Thon., 1999). Yet, the majority of the organizations says "borrow" mindfulness from a few successful competitors by monitoring what they have to say regarding the benefits of an innovation and what they are actually doing (Swanson \& Ramiller, 2004). In this study, through following our review, we noticed that mimetic pressures mainly come up from competitors. Therefore, this study spotlights on these pressures from competitors aspect, hence it is highly possible that knowledge maps potential adopters are subject to these pressures from competitors. Thus, we assumed that:

H9: Greater mimetic pressure from competitors leads to greater intent to adopt knowledge maps.

\subsection{Task Context}

Task context refers to the characteristics of the task, which basically include task complexity and task interdependences (Goodhue \& Thompson, 1995). The matching of the demands of the task and the capabilities of the technology that is the ability of the technology to support a task positively affects the adoption of IT innovation (Dishaw \& Strong, 1999). According to (Gupta, 2003) a little capability of technology with task requirements, might not result in benefits, since the technology is useless when it is behind the requirements of the task. Thus, to study the impact of task characteristics on knowledge map adoption Goodhue and Thompson's (1995) TTF model will be used as a theoretical basis. This study considers two characteristics of tasks: task complexity and task interdependences that may affect knowledge map adoption in software organizations.

\subsubsection{Task Complexity}

Task complexity or difficulty is one of the most essential factors that influencing IT innovation adoption as observed in many organizational studies. Many scholars have argued that the nature of the task complexity plays a necessary role in IT innovation adoption. With increasing task complexity, the intention for IT innovation adoption increased (DeSanctis \& Poole, 1994; Shaw, 1981). Therefore, if the decision makers perceived an IT innovation as a supporting tool in complex situations the potential adopted of that innovation may be increased especially if they realize the real benefits of that innovation.

In the context of software development organizations, tasks with high complexity, such as developing a big project, generally require a significant technology to facilitate task progression. Here, where the role of knowledge maps, shown significant. Knowledge maps provide an opportunity to achieve more understanding of a complex task situation as well as facilitates a common thoughtful between different stakeholders in software 
originations (Shih, 2011; Huang et al., 2006; Hansn \& Kautz, 2004). Knowledge mapping techniques primarily serve as a tool for human beings to better understand the structure of the complex tasks and their relationships so the application of knowledge maps on various types of organizations has gradually become popular particularly in software development organizations (Shih, 2011; Shih et.al., 2008; Huang et.al., 2006; Hansen \& Kautz, 2004; Hauck et al., 2001; Gordon, 2000; Chen et al., 1998). As a result, we assume that more complexity of the task leads to greater intent to adopt knowledge maps. The following hypothesis, therefore formulated:

H10: Greater task complexity will lead to a greater intent to adopt knowledge maps.

\subsubsection{Task Interdependence}

Besides task complexity task interdependence has been known as a second dimension of managerial tasks (Karim., Gupta \& Somers, 2004, Goodhu. \& Thompson 1995). Ordinarily, it is the degree to which a task is interconnected with other organizational units or tasks. In other words, it indicates the extent to which the ongoing task involves other organizational units or business jobs (Goodhu. \& Thompson, 1995). According to Kiggundu (1981) task interdependence consists of two types; received and initiated interdependence. When someone is dependent on the work of others, it is referred to as received task interdependence. In case someone affects the workflow of others, it is referred to as initiated task interdependence. It is all together the degree of 'interconnectedness' between jobs in which the success of one depends on the performance of others (Morgeson \& Humphrey, 2006; Kiggundu, 1983; Kiggundu, 1981).

The full literature has found that task interdependence has an effect on the behaviors of IT innovation adoption as well it has an important role in shaping organizational coordination mechanisms (Andres \& Zmud, 2002). Tasks with high interdependence require high levels of information exchange to develop effective task performance strategies, clarify task assignments, obtain performance feedback and make decisions (Andr. \& Zmu., 2002). That is, the more people are interdependent on one another, the more information and a rich exchange of data is needed to satisfy their needs (Karimi et al., 2004) thus they will become more intend to adopt a technology that offering these capabilities (Goodhue \& Thompson, 1995). Likewise, Jarvenpa \& Staple (2000) stated that, those whose work involves tasks that are interdependent with others should be motivated to use the technology more than those who act alone. Therefore, tasks with high interdependence, such as software development, generally require a significant technology to facilitate task processes.

In software development organizations people work fairly dependently, as instance, when managers have a coordinating function and need to interact with others, the same applies to decision makers, team's leaders or members of a team which need to exchange information with other people therefore, they require appropriate techniques that facilitate their interacted with colleagues or clients. Here, where the need for knowledge maps comes up. In laboratory studies, the effectiveness of knowledge map increased with increasing task interdependences (Shih, 2011; Shih et.al., 2008; Huang et.al., 2006; Hansen \& Kautz, 2004; Hauck et.al., 2001; Gordon, 2000; Chen et al., 1998). Thus, based on the above analysis of the literature, we assumed that high task interdependences might lead to a higher degree of knowledge map adoption. For this reason, the following hypothesis is put forth:

H 11: Greater task interdependence will lead to a greater intent to adopt knowledge maps.

\subsection{Individual Context}

In an organization, the decision of an IT innovation adoption is directly influenced by an individual's perception (Venkatech, 2003). According to Awa et.al. (2011) IT innovation adoption depends majorly on the useful, and/or emotional feelings of adopters, which reflect their perceptions, motivations and attitudes towards IT adoption. Here, in order to analyze the impact of individual characteristics on knowledge map adoption, UTAUT2 theory was deemed as a relevant part of the individual context. This study adopted social influence, hedonic motivation and behavioral Intentions. Since, these factors showed some relevance, strength in this study and may assist to predict the possibility of knowledge map adoption among software organizations.

\subsubsection{Social Influence}

Social influence has defined as the degree to which an individual perceives that important others believe he/she should utilize the new innovation (Venkatch, 2003). As a major determinant of behavioral intention, social influence construct is captured as social-factors in (MPCU), subjective-norm in (TPB/DTPB,C-TAM-TPB, and TRA), and image in (IDT). Each of these constructs even as they have different labels, they contain the implicit or explicit concept that the individual's behavior is influenced by the way in which they believe others will view them as a result of having adopted the technologies (Venkatsh et.al., 2003; Thompson et al., 1991). Empirical comparison established that the constructs listed above behave alike (Venkatesh et al., 2003). 
Behavior of individual has influenced by social influence throughout three mechanisms: internalization, identification and compliance. Whilst the first two mechanisms causing an individual to respond to potential social status gains and/or altering an individual's belief structure, the last mechanism (compliance) causes an individual to simply alter his/her intention in response to the social pressure, i.e. the individual intends to comply with the social influence (Venkatesh \& Dav., 2000; Warsh. 1980). Prior studies revealed that individuals are more probable to comply with the expectations of others when those referent others have the ability to punish non-behavior or reward the preferred behavior (e.g. Warshaw, 1980; French \& Raven, 1959) this compliance view is compatible with results in the literature of technology adoption that indicating reliance on the opinions of others is significant, particularly in the early stages of experience (Venkatesh \& Davis, 2000; Karahanna et al., 1999; Agarwal \& Prasad, 1997; Taylor \& Todd, 1995; Hartwick \& Barki, 1994; Thompson et al. 1994). Since the role of social influence in the context of software development organizations is a significant factor to be considered, particularly when less experienced or more junior staff tend to look up to what their peers recommend. According to Joseph Lee, et al. (2013) the role of social influence in the context of knowledge map adoption by software organizations is considered as a major determinant of behavioral intention. Derived from prior empirical evidences and theoretical arguments, the following hypothesis put forward:

H12: Social influences have a positive significant influence on behavioral intention to adopt knowledge maps.

\subsubsection{Hedonic Motivation}

One aspect of the extended of UTAUT to UTAUT2 by Venkatesh et.al. (2012) in their study of technology use by consumers is the integrating of a hedonic motivation factor in UTAUT2. According to Venkatesh et al. (2012) Hedonic motivation is defined as the pleasure or fun derived from using technologies, and it has been shown to play an important role in determining technologies adoption and use. In IS research, hedonic motivation has been found as a critical factor that influencing technology adoption directly and plays an important role in determining technology utilizing (e.g., Thon et.al., 2006; Brown \& Venkatesh, 2005; Heijden, 2004). Likewise, in the consumer context hedonic motivation has also been found to be an important determinant of technology adoption and use (e.g., Brow \& Venkatesh, 2005; Childer et.al., 2001). In the same vein, hedonic motivation has been found to be a key determinant of using a mobile technology (Dickinger et al., 2006) and social networking tool usage ( $\mathrm{Li} \& \mathrm{Lu}, 2011)$. In the case of knowledge maps adoption by software development teams, if the user experience a great pleasure in using knowledge maps functions, interface and other features, then the user's intention to adopt a knowledge map will be increased. The subsequent hypothesis is therefore proposed:

H13: Hedonic motivation has a significant and positive influence on behavioral intention to adopt knowledge maps.

\subsubsection{Behavioural Intentions}

Derived from the consistency of this variable in the adoption of the IT innovations in general in the UTAUT and UTAUT2, it can be established that behavioural intention to use knowledge map will give rise to the adoption of knowledge map. Hence, the following hypothesis can be formulated:

H14: Behavioural intention to use the knowledge map will have a significant positive influence on the adoption of the knowledge maps.

\section{Discussion and Conclusion}

In this article, we have proposed a new conceptual adoption model based on the TOE theoretical framework. Through conducting an in-depth literature review, the researcher uncovered initial concepts, constructs, and a set of preliminary detriments that may influence knowledge map adoption. The proposed conceptual model for the adoption of knowledge map by software organizations was founded by integrating two other theories, to the TOE framework, including the TTF, and the UTAUT2 theories. The factors covering five broad contexts (technological, organizational, environmental, task, and individual) that could potentially influence knowledge map adoption. As stated above the literature argues that the majority of the current research of knowledge map generally focuses on the technical aspects of mapping with a particular dearth of discussion on the factors that influencing the adoption of knowledge map. Therefore, we believe this model can offer a valuable tool for managers to understand the factors that influencing the adoption of knowledge map in order that they could proactively design further strategy to improve their employee's attitudes to adopt this technology (e.g. training strategies). So far, the initial research model is still untested. Thus, developing an instrument for survey and testing of the research model is crucial for future research.

\section{References}

Andres, H. P., \& Zmud, R. W. (2002). A Contingency Approach to Software Project Coordination. Journal of 
Management InformationS ystems, 18(3), 41-70.

Alam, S. S. (2009). Adoption of internet in Malaysian SMEs. Journal of Small Business and Enterprise Development, 16(2), 240-255. http://dx.doi.org/10.1108/14626000910956038

Awa, H. O., Eze, S. C., Urieto, J. E., \& Inyang, B. J. (2011). Upper echelon theory (UET): A major determinant of information technology (IT) adoption by SMEs in Nigeria. Journal of Systems and Information Technology, 13(2), 144-162. http://dx.doi.org/10.1108/13287261111135981

Alatawi, F. M. H., Dwivedi, Y. K., Williams, M. D., \& Rana, N. P. (2012). Conceptual model for examining knowledge amanagement system (KMS) adoption in public sector organizations in Saudi Arabia. Paper presented at the tGOV Workshop '12 (tGOV12), Brunei Universiti, West London.

Al-Gahtani, S. S., Hubona, G. S., \& Wang, J. (2007). Information technology (IT) in Saudi Arabia: Culture and the acceptance and use of IT. Information Management, 44(8), 681-691. http://dx.doi.org/10.1016/j.im. 2007.09.002

Al-Qirim, N. (2007). The adoption of eCommerce communications and applications technologies in small businesses in New Zealand. Electronic Commerce Research and Applications, 6, $462-473$. http://dx.doi.org/10.1016/j.elerap.2007.02.012

Azam, S., \& Taylor, D. (2011). Adopting standard business reporting (SBR) in Australia: Are CFOs persuaded by technology attributes? Critical Perspectives on Accounting. Florida, USA.

Brown, S. A., \& Venkatesh, V. (2005). Model of adoption of technology in households: A baseline model test and extension incorporating household life cycle. MIS Quarterly, 29(3), 399-426.

Baker, J. (2012). Information Systems Theory Explaining and Predicting (pp. 213-239).

Burt, R. S. (1987). Social Contagion and Innovation: Cohesion versus Structural Equivalence. American Journal of Sociology, 92(6), 1287-1335. http://dx.doi.org/10.1086/228667

Beatty, R. C., Shim, J. P., \& Jones, M. C. (2001). Factors influencing corporate web site adoption: A time-based assessment. Information \& Management, 38, 337-354. http://dx.doi.org/10.1016/S0378-7206(00)00064-1

Chau, P. Y. K., \& Tam, K. Y. (1997). Factors affecting the adoption of open systems: An exploratory study. MIS Quarterly, 1-24. http://dx.doi.org/10.2307/249740

Doolin, B., \& Troshani, I. (2007). Organizational adoption of xbrl. Electronic Markets, 17(3), $199-209$. http://dx.doi.org/10.1080/10196780701503195

Dishaw, M. T., Strong, D. M., \& Brandy, D. B. (2002). Extending the task-technology fit model of self-efficacy constructs. In R. Ramsower, \& J. Windsor (Eds.), Proceedings of the 8th Americas conference on information systems. Dallas, TX.

Davis, F. D. (1989). Perceived Usefulness, Perceived Ease of Use, and User Acceptance of Information Technology. MIS Quarterly, 13(3), 319-339. http://dx.doi.org/10.2307/249008

Dishaw, Mt., \& Strong, Dm. (1999). Extending the technology acceptance model with task technology fit constructs. Information \& Management, 36(1), 9-21. http://dx.doi.org/10.1016/S0378-7206(98)00101-3

Deephouse, D. J. (1996). Does isomorphism legitimate? Academy of Management Journal, 39(4), $1024-1039$. http://dx.doi.org/10.2307/256722

DeSanctis, G., \& Poole, M. S. (1994). Capturing the Complexity in Advanced Technology Use: Adaptive Structuration Theory. Organization Science, 5(2), 121-147.

Davenport, B. T. H., Prusak, L., \& Webber, A. (2000). Working Knowledge: How Organizations Manage What They Know. Harvard Business Press.

Dang, Y., Zhang, Y., Hu, P. J. -H., Brown, S. a., \& Chen, H. (2011). Knowledge mapping for rapidly evolving domains: A design science approach. Decision Support Systems, 50(2), 415-427. http://dx.doi.org/10.1016/ j.dss.2010.10.003

DiMaggio, P. J., \& Powell, W. W. (1983). The iron cage revisited: Institutional isomorphism and collective rationality in organizational fields. American Sociological Review, 48(2), 147-160. http://dx.doi.org/ $10.2307 / 2095101$

Eppler, M. J. (2001). Making Knowledge Visible Through Intranet Knowledge Maps : Concepts, Elements, Cases. In 34th Hawaii International Conference on System Sciences (pp. 1-10). 
Fuller, M. A., Hardin, A. M., \& Scott, C. L. (2007). Diffusion of virtual innovation. The DATA BASE for Advances in Information Systems, 38(4), 40-44. http://dx.doi.org/10.1145/1314234.1314243

Fahey, L., \& Prusak, L. (1998). The Eleven Deadliest Sins of Knowledge Management. California Management Review, 40(3), 265-276.

Goodhue, D. L., \& Thompson, R. L. (1995). Task-technology fit and individual performance. MIS Quarterly, 19(2), 213-236. http://dx.doi.org/10.2307/249689

Grover, V. (1993). An empirically derived model for the adoption of customer-based interorganizational systems. Decision Sciences, 24(3), 603-640. http://dx.doi.org/10.1111/j.1540-5915.1993.tb01295.x

Gordon, J. L. (2000). Creating knowledge maps by exploiting dependent relationships. Knowledge-based Systems, 13(2-3), 71-79. http://dx.doi.org/10.1016/S0950-7051(00)00048-4

Henderson, D., Sheetz, S. D., \& Trinkle, B. S. (2012). The determinants of inter-organizational and internal in-hounse adoption of XBRL: A structural equation model. International Journal of Accounting Information Systems, 13, 109-140. http://dx.doi.org/10.1016/j.accinf.2012.02.001

Hansen, B. H., \& Kautz, K. (2004). Knowledge Mapping: A Technique for Identifying Knowledge Flows in Software Organisations. Springer-Verlag Berlin Heidelberg, 126-137.

Iacovou, C. L., Benbasat, I., \& Dexter, A. S. (1995). Electronic data interchange and small organizations: Adoption and impact of technology. MIS Quarterly, 465-485. http://dx.doi.org/10.2307/249629

Joseph, \& Dieter. (2013). Knowledge mapping: encouragements and impediments to adoption. Journal of Knowledge Management, 17(1), 16-28. http://dx.doi.org/10.1108/13673271311300714

Jeyaraj, A., Rottman, J. W., \& Lacity, M. C. (2006). A review of predictors, linkages, and biases in IT innovation adoption research. Journal of Information Technology, 21, 1-23. http://dx.doi.org/10.1057/palgrave.jit. 2000056

Jarvenpaa, S. L., \& Ives, B. (1991). Executive Involvement and Partici pation in the Management of Information Technology. MIS Quarterly, 15(2), 205-227.

Khalifa, M., \& Davison, R. M. (2006). SME adoption of IT: The case of electronic trading systems. IEEE Transactions of Engineering Management, 53(2), 275-284. http://dx.doi.org/10.1109/TEM.2006.872251

Kuan, K. K. Y., \& Chau, P. Y. K. (2001). A perception-based model for EDI adoption in small businesses using a technology-organization-environment framework. Information \& Management, 38, 507-521. http://dx.doi. org/10.1016/S0378-7206(01)00073-8

Low, C., Chen, Y., \& Wu, M. (2011). Understanding the determinants of cloud computing adoption. Industrial Management \& Data Systems, 111(7), 1006-1023. http://dx.doi.org/10.1108/02635571111161262

Lee, O. K., Wang, M., Lim, K. H., \& Peng, Z. (2009). Knowledge management systems diffusion in Chinese enterprises: A multistage approach using the technology-organization-environment framework. Journal of Global Information Management, 17(1), 70-84. http://dx.doi.org/10.4018/jgim.2009010104

Lin, T -C., \& Huang, C -C. (2008). Understanding knowledge management system usage antecedents: an integration of social cognitive theory and task technology fit. Information \& Management, 45(6), 410-417. http://dx.doi.org/10.1016/j.im.2008.06.004

Lin, H. F., \& Lin, S. M. (2008). Determinants of e-business diffusion: A test of the technology diffusion perspective'. Technovation, 28, 135-145. http://dx.doi.org/10.1016/j.technovation.2007.10.003

Lertwongsatien, C., \& Wongpinunwatana, N. (2003). E-commerce Adoption in Thailand: An Empirical Study of Small and Medium Enterprises (SMEs). Journal of Global IT Management, 6(3), 67-83.

Lederer, A. L., \& Mendelow, A. L. (1988). Convincing top management of the strategic potential of information systems. MIS Quarterly, 12(4), 526-536. http://dx.doi.org/10.2307/249127

Liu, H., Ke, W., Wei, K. K., Gu, J., \& Chen, H. (2010). The role of institutional pressures and organizational culture in the firm's intention to adopt internet-enabled supply chain management systems. Journal of Operations Management, 28, 372-384. http://dx.doi.org/10.1016/j.jom.2009.11.010

Melville, N., \& Ramirez, R. (2008). Information technology innovation diffusion: An information requirements paradigm. Information Systems Journal, 18(3), 247-273. http://dx.doi.org/10.1111/j.1365-2575.2007. 00260.x 
Moore, G. C., \& Benbasat, I. (1991). Development of an Instrument to Measure the Perceptions of Adopting an Information Technology Innovation. Information Systems Research, 2(3), 192-222. http://dx.doi.org/10. 1287/isre.2.3.192

Nelson, M. L., \& Shaw, M. J. (2003). The adoption and diffusion of interorganizational system standards and process innovation, standard Making: A Critical Research Frontier for Information Systems. MISQ Special Issue Workshop.

Oliveira, T., \& Martins, M. F. (2010). Understanding e-business adoption across industries in European countries. Industrial Management and Data System, 110(9), 1337-1354. http://dx.doi.org/10.1108/026355710 11087428

Premkumar, G. (2003). A meta-analysis of research on information technology implementation in small business. Journal of Organizational Computing and Electronic Commerce, 13(2), 91-121. http://dx.doi.org/10.1207/ S15327744JOCE1302_2

Premkumar, G., \& Roberts, M. (1999). Adoption of new information technologies in rural small businesses. Omega: The International Journal of Management Science, 27(4), 467-484. http://dx.doi.org/10.1016/ S0305-0483(98)00071-1

Purvis, R. L., Sambamurthy, V., \& Zmud, R. W. (2001). The Assimila tion of Knowledge Platforms in Organizations: An Empirical Investigation. Organization Science, 12(2), 117-135. http://dx.doi.org/10.1287/ orsc.12.2.117.10115

Plouffe, C. R., Hulland, J. S., \& Vandenbosch, M. (2001). Research Report: Richness Versus Parsimony in Modeling Technology Adoption Decisions - Understanding Merchant Adoption of a Smart Card-Based Payment System. Information Systems Research, 12(2), 208-222. http://dx.doi.org/10.1287/isre.12.2. 208.9697

Quinn J. B. (1985). Managing innovation: controlled chaos. Harvard Business Review, 63(3), 73-84.

Renukappa, \& Egbu, C. O. (2004). Knowledge Mapping: Concepts and Benefits for a Sustainable Urban Environment. In the 20th Annual Conference Association of Researchers in Construction Management (ARCOM) (Vol. 2, pp. 1-12).

Ramdani, B., Kawalek, P., \& Lorenzo, O. (2009). Knowledge management and enterprise systems adoption by SMEs: Predicting SMEs adoption of enterprise systems. Journal of Enterprise Information Management, 22(1-2), 10-24. http://dx.doi.org/10.1108/17410390910922796

Rogers, E. M. (2003). Diffusion of Innovations (5th ed.). New York: Free Press.

Rogers, E. (1995). Diffusion of innovations (4th ed.). New York: The Free Press.

Shih, J. (2012). A Comparison of Knowledge Map and Keyword Search in Knowledge Retrieval, 1596-1601.

Shaw, M. E. (1981). Group Dynamics: The Psychology of Small Group Behavior (3rd ed.), McGraw-Hill Book Company, New York.

Saedi, A., \& Iahad, N. A. (2013). An Integrated Theoretical Framework for Cloud Computing Adoption by Small and Medium-Sized Enterprises.

Son, J. Y., \& Benbasat, I. (2007). Organizational buyers' adoption and use of B2B electronic marketplaces: efficiency- and legitimacy-oriented perspectives. Journal of Management Information Systems, 24(1), 55-99. http://dx.doi.org/10.2753/MIS0742-1222240102

Stair, R. M., \& Reynolds. (1998). Principles of information systems: A managerial approach (3rd ed.). Course Publishers.

Srivastava, S. (1983). The Executive Mind Jossey-Bass, San Francisco.

Teo, T. S. H., \& Ranganathan, C. (2004). Adopters and non-adopters of E-Procurement in Singapore. OMEGA. The International Journal of Management Science, 37(5), 972-987. http://dx.doi.org/10.1016/j.omega.2008. 11.001

Teo, H. H., Wei, K. K., \& Benbasat, I. (2003). Predicting Intention to Adopt Interorganizational Linkages: An Institutional Perspective. MIS Quarterly, 27(1), 19-49.

Tan, \& Felix, T. C. (2010). A perception-based model for technological innovation in small and medium enterprises. Paper presented at 18th European Conference on Information Systems (ECIS). Paper 33. 
Thong, J. Y. L. (1999). An integrated model of information systems adoption in small businesses. Journal of Management Information Systems, 15(4), 187-214.

Tornatzky, L. G., \& Fleischer, M. (1990). The process of Technological Innovation. Lexington: Lexington Books.

Tiwana, A. (1999). Knowledge Management Toolkit (1st ed., pp. 1-482). Prentice Hall PTR.

Uzoka F. M. E. (2008). Organizational Influences on E-commerce adoption in a developing country context using UTAUT. International Journal of Business Information Systems, 3(3), 300-316. http://dx.doi.org/ 10.1504/IJBIS.2008.017287

Vail, E. F. (1999). Knowledge Mapping: Getting Started With Knowledge Management. Information Systems Management, 16(4), 37-41. http://dx.doi.org/10.1201/1078/43189.16.4.19990901/31199.3

Venkatesh, V., \& Thong, J. (2012). Consumer acceptance and use of information technology, extending the unified theory of acceptance and use of technology. MIS quarterly, 36(1), 157-178.

Venkatesh, V., Morris, M. G., Davis, G. B., \& Davis, F. D. (2003). User acceptance of information technology: Toward a unified view. MIS Quarterly, 27(3), 425-478.

Ven, K., \& Verelst, J. (2011). An empirical investigation into the assimilation of open source server software. Communications of the Association for Information Systems, 28(9), 117-140.

Wexler, M. N. (2001). The who, what and why of knowledge mapping. Journal of Knowledge Management, 5(3), 249-264. http://dx.doi.org/10.1108/EUM0000000005868

Wang, M., Huang, C., \& Yang, T. (2012). Acceptance of Knowledge Map Systems: An Empirical Examination of System Characteristics and Knowledge Map Systems Self-efficacy. Asia Pacific Management Review, 17(3), 263-280.

Wang, Y. S., \& Shih, Y. W. (2009). Why do people use information kiosks? A validation of the unified theory of acceptance and use of technology. Government Information Quarterly, 26(1), 158-165. http://dx.doi.org/ 10.1016/j.giq.2008.07.001

Yoon, T. E., \& George, J. F. (2013). Why aren't organizations adopting virtual worlds? Computers in Human Behavior, 29, 772-790. http://dx.doi.org/10.1016/j.chb.2012.12.003

Yoon, T. (2009). An empirical investigation of factors affecting organizational adoption of virtual worlds. Doctoral Dissertation, The Florida State University College of Business.

Zhou, T. (2012). Examining location-based services usage from the perspective of unified theory of acceptance and use of technology and privacy risk. Journal of Electronic Commerce Research, 13(2).

Zhu, K., Dong, S., Xu, S. X., \& Kraemer, K. L. (2006). Innovation diffusion in global contexts: Determinants of post-adoption digital transformation of European companies. European J. of Information Systems, 15(6), 601-616. http://dx.doi.org/10.1057/palgrave.ejis.3000650

Zhu, K., Kraemer, K. L., \& Xu, S. (2003). Electronic business adoption by European firms: A cross-country assessment of the facilitators and inhibitors. European Journal of Information Systems, 12, 151-268. http://dx.doi.org/10.1057/palgrave.ejis.3000475

\section{Copyrights}

Copyright for this article is retained by the author(s), with first publication rights granted to the journal.

This is an open-access article distributed under the terms and conditions of the Creative Commons Attribution license (http://creativecommons.org/licenses/by/3.0/). 